\title{
Analysis of Higher Educational Offerings in Operations Management
}

\author{
Heather Lutz* \\ Department of Supply Chain and Information Systems \\ Smeal College of Business \\ The Pennsylvania State University \\ 470 Business Building \\ University Park, PA 16802 \\ hlutz@psu.edu
}

Heather Lutz is a Clinical Assistant Professor of Supply Chain Management in The Smeal College of Business at The Pennsylvania State University, State College, PA. Her research interests include supply chain management, humanitarian supply chain management, and priority queues. Dr. Lutz received a BS in Mathematics from Penn State, an MBA in Logistics, Operations and Materials Management from The George Washington University and received her Ph.D. in Supply Chain Management from Syracuse University. Dr. Lutz's industry experience includes positions as a logistics analyst, commodity manager and a program manager at Hewlett Packard and Agilent Technologies.

\author{
Laura Birou \\ Department of Marketing \\ University of Central Florida \\ College of Business Administration \\ 4000 Central Florida Blvd, P.O. Box 161991 \\ Orlando, FL 32816-1991 \\ Laura.Birou@ucf.edu
}

Laura Birou currently serves on the faculty of the University of Central Florida while also serving as a Director of North America for the International Institute for Advanced Purchasing and Supply. Dr. Birou is a graduate of Michigan State University with a Ph.D. in Business Administration specializing in Purchasing, Operations and Strategic Management. Her research efforts are currently devoted to Humanitarian Supply Chain Management, Sustainability, Supplier Relationship Management and Supply Chain Management Education. She has publications appearing in the Journal of Operations Management, International Journal of Purchasing and Materials Management, the International Journal of Physical Distribution and Logistics Management, and Production and Inventory Management Journal. 


\section{Vijay Kannan \\ Department of Management \\ Utah State University \\ Huntsman School of Business \\ 412 Business \\ Logan, UT 84322-3500 \\ vijay.kannan@usu.edu}

Vijay R. Kannan is Professor of Operations Management and Executive Director of International Programs in the Jon M. Huntsman School of Business, Utah State University. He received his BSc from the London School of Economics, MBA from Indiana University, and PhD from Michigan State University. Professor Kannan's research on cellular manufacturing, supply chain management, and manufacturing strategy has appeared in journals including Decision Sciences, the Journal of Supply Chain Management, the International Journal of Operations and Production Management, and Academy of Management Journal of Learning and Education.

* Corresponding author 


\title{
Analysis of Higher Educational Offerings in Operations Management
}

\author{
Abstract \\ This paper presents the results of a large-scale benchmarking study of Operations \\ Management (OM) courses in higher education. The goal of the research is to drive \\ continuous improvement in the quality and value of the educational experience in \\ academic institutions, and inform the training, development, and recruitment efforts of \\ SCM professionals. A content analysis of a large sample of OM course syllabi was \\ carried out to identify the content of both undergraduate and graduate courses, and the \\ relative importance attached to individual topics. Gaps between topical coverage and \\ what industry experts have identified as the important knowledge, skills and abilities are \\ also identified
}

\section{Keywords: Benchmarking, Supply Chain Management, Operations Management, Education, Curriculum, Syllabi}

\section{Introduction}

Experts globally agree that if the value-added capabilities of product-service delivery processes are not improved, economies will suffer and standards of living will fall (Ahmad, 2013; Hayes et.al. 1989; Takeuchi and Nonaka 1986). In response, organizations worldwide are competing using strategies driven by the principle of valueadded. Their pursuit of providing value to customers has resulted in the adoption of a variety of continuous improvement efforts aimed at reengineering product-service 
delivery processes. The Operations Management (OM) discipline gives university students the skills necessary to critically evaluate and improve these delivery processes. It is thus incumbent on those responsible for the delivery of OM education to assess the value-added of the processes they use relative to the needs of the marketplace (i.e. students and employers).

The objective of this research is to determine the current state of OM education with regards to course content, teaching styles, and assessment techniques. The study, an extension of a study on the content of logistics courses (Lutz and Birou, 2013), focuses specifically on OM courses at the undergraduate and graduate levels, and seeks to provide academics with a reference point they can use to benchmark their courses against common practices. In addition, it provides participants new to the academic profession with information to draw upon when developing their own courses. The results of the study will also enable corporate recruiters to evaluate the academic content of the programs from which they recruiting, and the alignment between this and the competencies they seek in new hires.

\section{Benchmarking in Higher Education}

The application of benchmarking to Higher Education (HE) is not new. Alstete (1995) recognized that the future of HE in the United States would be marked by higher competition for students, and increasing expectations from society for value from the educational process. He further suggested that benchmarking represented a means of improving the quality of the educational process. Leslie and Fretwell (1996. p. 26) stated 
that "The financial health of virtually every American college or university depends directly on the tuition-paying, appropriation-generating undergraduate students. Giving undergraduates good value for what they, their parents, and the public invest in higher education is the single most important thing the institution can do to get out of 'the mess"”.

European universities, faced with reduced funding and increasing competition, have also seen benchmarking as a way of improving quality, efficiency, and cost-effectiveness, and increasing their value-added proposition. According to Jackson (2001, p. 219), "Benchmarking is one method HE institutes (HEIs) can use to help themselves achieve this objective and to demonstrate to funding councils that they are providing value for the public investment". Moreover

“...in the global market of higher education there are clearly competitive advantages in establishing and maintaining a reputation for providing good quality education, high academic standards and world class research output. UK universities are under increasing pressure to show how they perform relative to universities in the global community and there is growing interest in transnational benchmarking to make reliable international comparisons and learn from other HE systems".

The competitive challenges faced by institutions in Europe led to the signing, by 29 countries, of the Bologna Declaration. This sought to address the 'erosion' of effectiveness in the quality of HE (Jeliazkova and Westerheijden, 2002), through a call for internationalization, standards, peer-review process and to identify and share best practice.

In the context of business schools, benchmarking has been a key component of the efforts of the Association to Advance Collegiate Schools of Business International (AACSB). 
AACSB developed their first accreditation standards in 1919, and in 1991 adopted a process by which schools and colleges were evaluated by assessors from peer institutions with similar missions. While historically driven by the U.S. academic market, performance standards and expectations were amended in 2003 to reflect the increasing numbers of business schools globally that sought accreditation. However, the focus of the accreditation review process was until recently on factors such as strategic planning, an institution's resource based, and its research productivity. More recently, accreditation standards were updated to incorporate 'Assessment of Learning', or the evaluation of learning outcomes. From a content perspective, AACSB has, by design, not been prescriptive. In the context of OM for example, the only requirement in Standard 9 is that curricula include 'Systems and processes in organizations, including planning and design, production/operations, supply chains, marketing, and distribution, schools'.

\section{Prior Studies of OM Courses}

Visich and Khumawala (2006) presented a comprehensive review of issues in OM education and training, including what courses and programs should look like, and the interface between academia and practitioner needs. However, an important observation that can be made from their work is that despite changes in the discipline, no recent effort has been made to survey what OM courses look like today or how they align with the needs of industry, and what the implications are for future course innovation.

As part of a broader study of courses in operations and quantitative methods at twenty top ranked MBA programs in the U.S, Carraway and Freeland (1989) examined OM courses. 
Of twelve schools to report topical coverage, all included inventory and quality, and at least two thirds included strategy, capacity, process analysis, just in time, aggregate planning, material requirements planning, scheduling, and project management. On average, $13 \%$ of course time was devoted to process analysis, with a further 9 to $11 \%$ each spent on strategy, inventory, and scheduling. While no explicit statement was made regarding the relative balance between manufacturing and services, topical coverage coupled with course titles suggested a significant emphasis on manufacturing, but with a shift towards services. Assessment was carried out largely by way of exams, with typically $50 \%$ of a course grade depending on exam performance, and $25 \%$ each on written analyses and class participation. Seventy five percent of courses relied on the use of a textbook.

The focus of Goffin (1996) was on ten leading European MBA programs. Findings showed that course objectives consistently mentioned developing an understanding of the role of operations. There was considerable divergence in terms of other objectives, but many revolved around understanding tactical issues. Courses tended to have a more manufacturing (average of $66 \%$ of course content) than service focus, and emphasized tactical issues (70\%) over strategic issues. However, in both cases there was considerable variation across courses. With respect to topical coverage, the role of operations management, and total quality management were a component of all courses examined. Processes, supply chain management, inventory management, capacity management, and planning and control were taught in at least six of the classes. Process reengineering, new product/process development, project management, international operations, time based 
competition, and cost analysis were taught in four or fewer classes. Exams on average accounted for almost $60 \%$ of the students' course grades, while written assignments that emphasized analysis were also a significant component of overall assessment.

Van Wassenhove and Corbey (1998) used a similar approach to that used by Goffin to explore OM courses at the top 20 MBA programs in the U.S. Their results paralleled those of Goffin. They also found that course objectives emphasized understanding the role of operations in organizations but were more likely to make explicit reference to understanding the strategic significance of operations, customer focused strategy and tactics, and the significance or different processes. Courses tended to be more manufacturing and tactics focused than their European counterparts. In terms of topical coverage, all courses again covered the role of operations. However, while operations strategy, quality management, supply chain management, processes capacity, and inventory were again typically included, U.S. courses were more likely to cover processes but less likely to cover quality management. Exams and class participation were used almost universally to assess student performance, the latter representing a significant contrast from Goffin's findings. An additional point of divergence between the two samples was that while European courses were more likely to utilize textbooks, U.S courses tended to rely on course packs and books other than textbooks.

Studies have also explored the content of the undergraduate OM courses. Willis and Bass (1989) identified 18 topics that were covered at 72 schools surveyed. Four topics, inventory management, material requirements planning, statistical quality control, and 
forecasting, were taught at $70 \%$ or more of the schools. A further six were taught at $60 \%$ or more of the schools; Just-in-Time, Location, Project Management, Capacity, Layout, and Master Planning. Similar to the findings of Carraway and Freeland, they observed that there was wide variation in the proportion of course time dedicated to individual topics. Raiszadeh and Ettkin (1989) conducted a survey of over four hundred schools. While not providing detailed breakdowns of topical coverage, they noted that while over $40 \%$ of courses included at least three hours on forecasting, inventory lot sizing, and material requirements planning, only $25 \%$ did the same for strategy. They also noted that while over $60 \%$ of courses had a moderate emphasis on services, close to $30 \%$ had little if any emphasis on this sector. In terms of pedagogy, almost all courses placed at least moderate emphasis on the use of lectures. Ducharme and Lewis (1987) approached the question of course content by examining the percent of time spent on topics drawn from the American Production and Inventory Control Society (APICS) certification tests. They identified that on average, $45 \%$ of class time was dedicated to the topics inventory management, material requirements planning, production activity control, master planning, and capacity planning.

Summarizing the results of prior studies, two important conclusions can be drawn. First, fifteen years have passed since the content of classes in OM has been comprehensively assessed, and almost a quarter decade in the context of undergraduate courses. Second, OM courses have historically emphasized tools and tactics, and had a strong focus on the manufacturing sector. The business environment has however changed significantly in the last two decades. One of the ways in which this is most evident is the increased 
strategic focus of firms on how they produce and deliver products and, in particular, services, in the marketplace given time, cost, and quality pressures. What makes the evaluation of OM classes particularly important is that the courses are often students' initial, and often, only exposure to issues associated with value creation via productservice delivery systems.

\section{Methodology}

In 2009, faculty members identified from membership lists of the Council of Supply Chain Management Professionals (CSCMP) and Institute for Supply Management (ISM) were contacted electronically with a request to share syllabi in the realm of supply chain management, including operations, purchasing, and logistics ${ }^{1}$. They were advised of the purpose of the study, and that the unit of analysis was thus a course, not a curriculum or program. Corresponding syllabi could correspond to undergraduate, graduate, or executive education courses. In some cases, faculty members provided one or multiple syllabi themselves, whereas others directed the authors to a website from which syllabi could be acquired. A response rate of $25 \%$ yielded a total of 174 syllabi deemed by the authors as corresponding to OM courses. Syllabi came from 91 universities in 5 countries, though only six percent of syllabi came from institutions outside the U.S. Consequently, the analysis of the syllabi that follows is based on a combined sample of syllabi received. Figure 1 summarizes the composition of the sample by geography and course level.

\footnotetext{
${ }^{1}$ The present study is part of a broader study of OM, supply chain management, and logistics education.
} 
Figure 1 Composition of sample by geography, course level

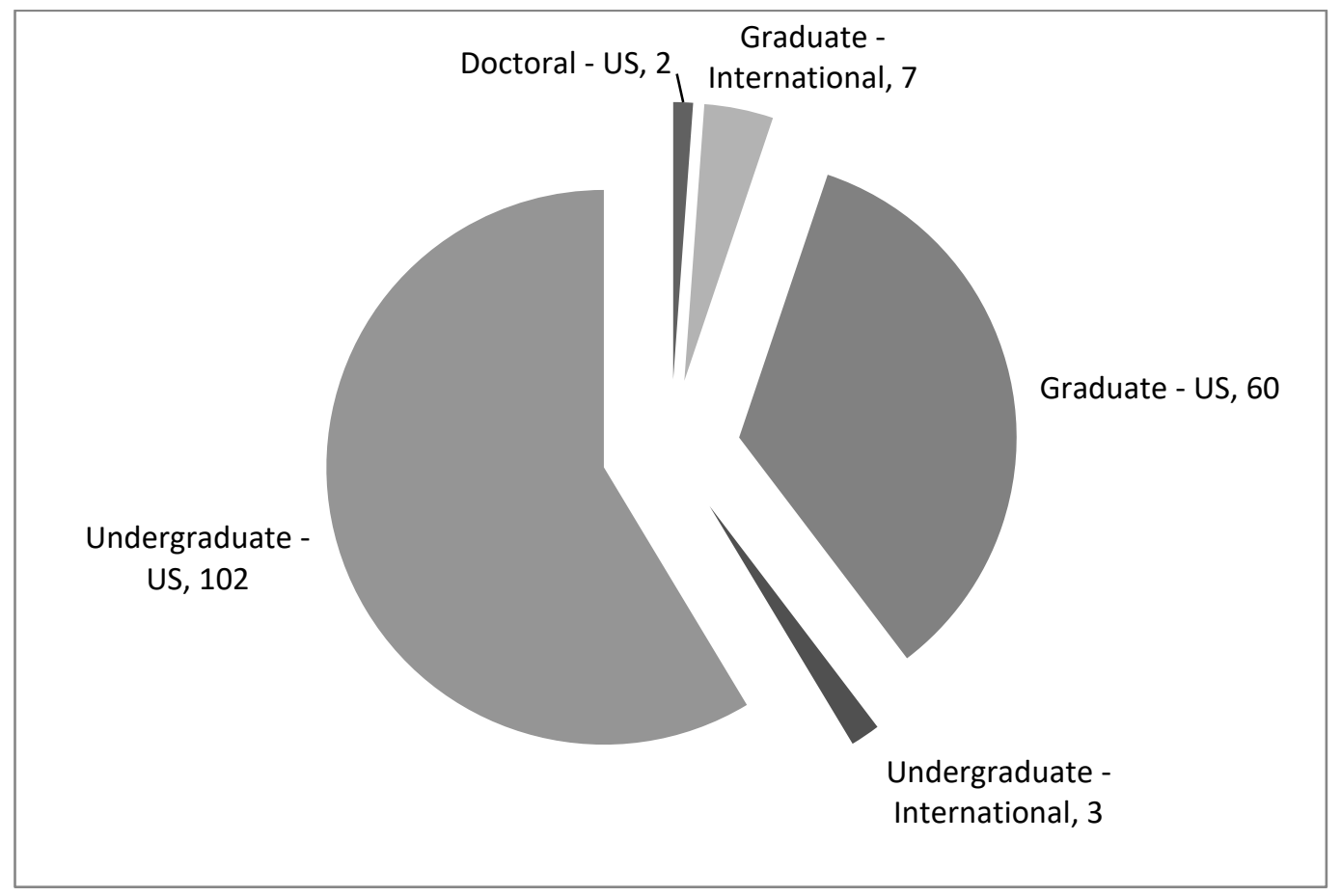

Content analysis provides a set of procedures that can be used to make valid inferences from material, and allows for the systematic evaluation of communication at many levels (Kolbe and Burnett, 1991). Quantitative descriptive analysis (Trochim and Donnelly, 2007) was the specific approach used as this makes it possible to quantitatively describe the topics that were listed frequently in the syllabi. Content attributes of each syllabus were coded by two trained individuals. The specific items coded included the level of class (undergraduate, graduate, doctoral, distance, executive), duration and contact time, specific topics covered, textbook(s), assignments (papers, cases, etc.), and the assessment methods utilized (including the weights for each method in final grade calculations). Any discrepancies in the coding were reconciled by one of the authors. The inter-rater reliability was 95 percent. 


\section{Results}

The presentation of results will follow the order of a typical syllabus, i.e., learning objectives, teaching style, grading schema, and finally course topics. It will conclude with a gap analysis by comparing what topics are being taught to the needs or demands of industry.

\section{Learning Objectives}

Most syllabi included specific course learning objectives. While objectives varied by course and level, several themes emerged. At the undergraduate level, syllabi included as many as ten learning objectives, most had a single learning objective that was framed around understanding the role and importance of OM. Some syllabi listed learning objectives that linked directly to specific course content, expectations of students, and/or

outcomes. Not surprisingly, as the number of objectives increased, the objectives became more specific. Similarly, most graduate courses had one main learning objective, though some had as many as ten. The main objective typically revolved around understanding the strategic roles and issues related to operations management within an organization, and how they relate to other business functions.

\section{Teaching Style}

The skill development approach developed by van Hoek (2001) was used to analyze teaching styles. This approach uses the types of class assignment to characterize teaching style in terms of whether they lend themselves to the development of research skills or 
market driven skills, see Figure 2. While research projects are seen as developing research skills, cases are viewed as cultivating the applied decision making skills sought by employers. van Hoek called for courses to adopt an "Integrative skill development approach" that incorporates both case and research based analysis. This was seen as better preparing students for the 'real world'.

Figure 2 Teaching skills framework

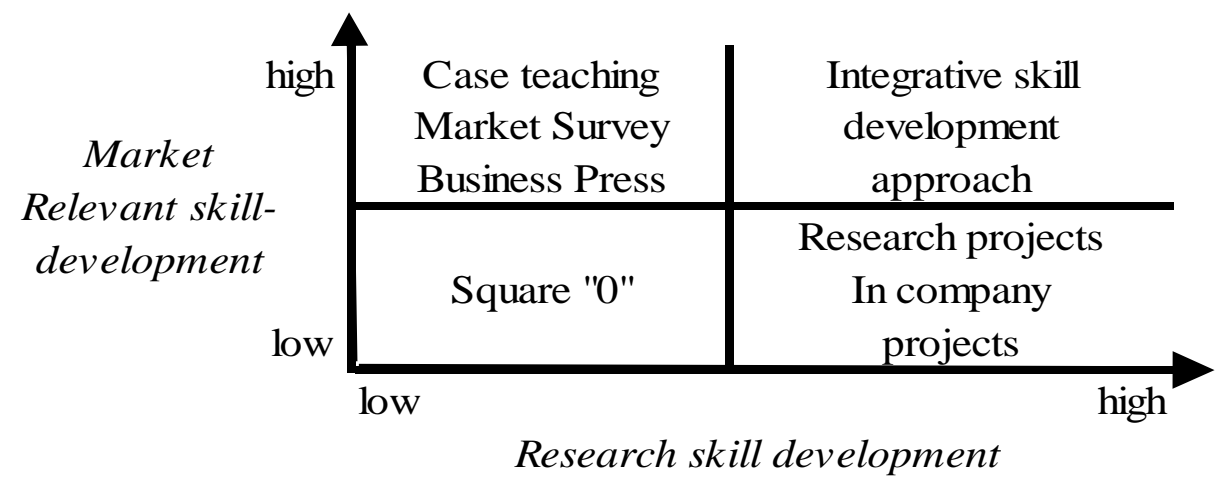

Source: van Hoek, R.I. (2001), "Logistics education-achieving market and research driven skill development", International Journal of Physical Distribution \& Logistics Management, Vol. 31 Nos 7/8, p. 508.

Syllabi were coded according to whether a class utilized cases, research projects, neither (Square "0”), or both (Integrative Approach). The percentages of syllabi corresponding to each category are illustrated in Figure 3. The results indicate that both undergraduate and graduate level courses rely heavily on research projects alone to develop skills. At the undergraduate level, relatively few courses utilize cases or a combination of cases and research projects, but conversely, the absence of both is not uncommon. The latter observation suggests the emphasis of courses is on content acquisition rather than skill development/application. This is however consistent with the underlying objective of 
undergraduate classes as suggested above, to develop an understanding of the role and importance of OM. Among graduate classes, few classes use neither cases nor research projects, with the distribution of syllabi across the three remaining quadrants of the matrix approximately uniform. This suggests that the focus of courses is on application and skill development, or context rather than content, and is consistent with the objective of developing an understanding of strategic roles and issues.

Figure 3 Current state of pedagogy in OM education

\begin{tabular}{|c|c|c|}
\hline $\begin{array}{l}\text { high } \\
\text { Market }\end{array}$ & $\begin{array}{c}\text { Case Assignments } \\
\text { U: } 15.84 \% \\
\text { G: } 29.69 \%\end{array}$ & $\begin{array}{c}\text { Integrative Approach } \\
\text { U: } 16.83 \% \\
\text { G: } 26.56 \%\end{array}$ \\
\hline $\begin{array}{r}\text { development } \\
\text { low }\end{array}$ & $\begin{array}{c}\text { Square "0" } \\
\text { U: } 28.71 \% \\
\text { G: } 12.5 \%\end{array}$ & $\begin{array}{c}\text { Research Projects } \\
\text { U: } 38.61 \% \\
\text { G: } 35.94 \%\end{array}$ \\
\hline
\end{tabular}

Key: U: Undergraduate classes G: Graduate classes

\section{Grading Schema}

All but three syllabi provided details of grading schema. Figure 4 illustrates the percentage of courses that used particular assessment techniques. Almost all undergraduate courses use final exams, and approximately $70 \%$ use mid-term exams. Assessments that tend to emphasis application or give students practice in developing mastery of specific topics (i.e., cases, projects, and homework) were found in only $33 \%$ (cases) to 55\% (projects/papers) of courses. While not surprising, this is an important observation. Consistent as it is with the underlying learning objective of undergraduate 
classes of developing an understanding of the role and nature of OM, one can speculate that it also suggests a desire on the part of instructors to minimize the administrative burden associated with grading, particularly when classes are taught to large numbers of students. At the graduate level, final exams are also used frequently but their use is less common than in undergraduate classes. Noticeably fewer syllabi indicated the use of midterm exams. Cases, projects, and participation are however more prevalent as a mode of assessment than in undergraduate classes, as are cases and research papers. This is consistent with the underlying objective of graduate course that revolves around understanding the strategic roles of OM, but may also be a reflection of factors such as smaller class sizes than for undergraduate classes, and a more sophisticated student population that can deliver applied work that faculty are more inclined to grade.

Figure 4 Assessment techniques

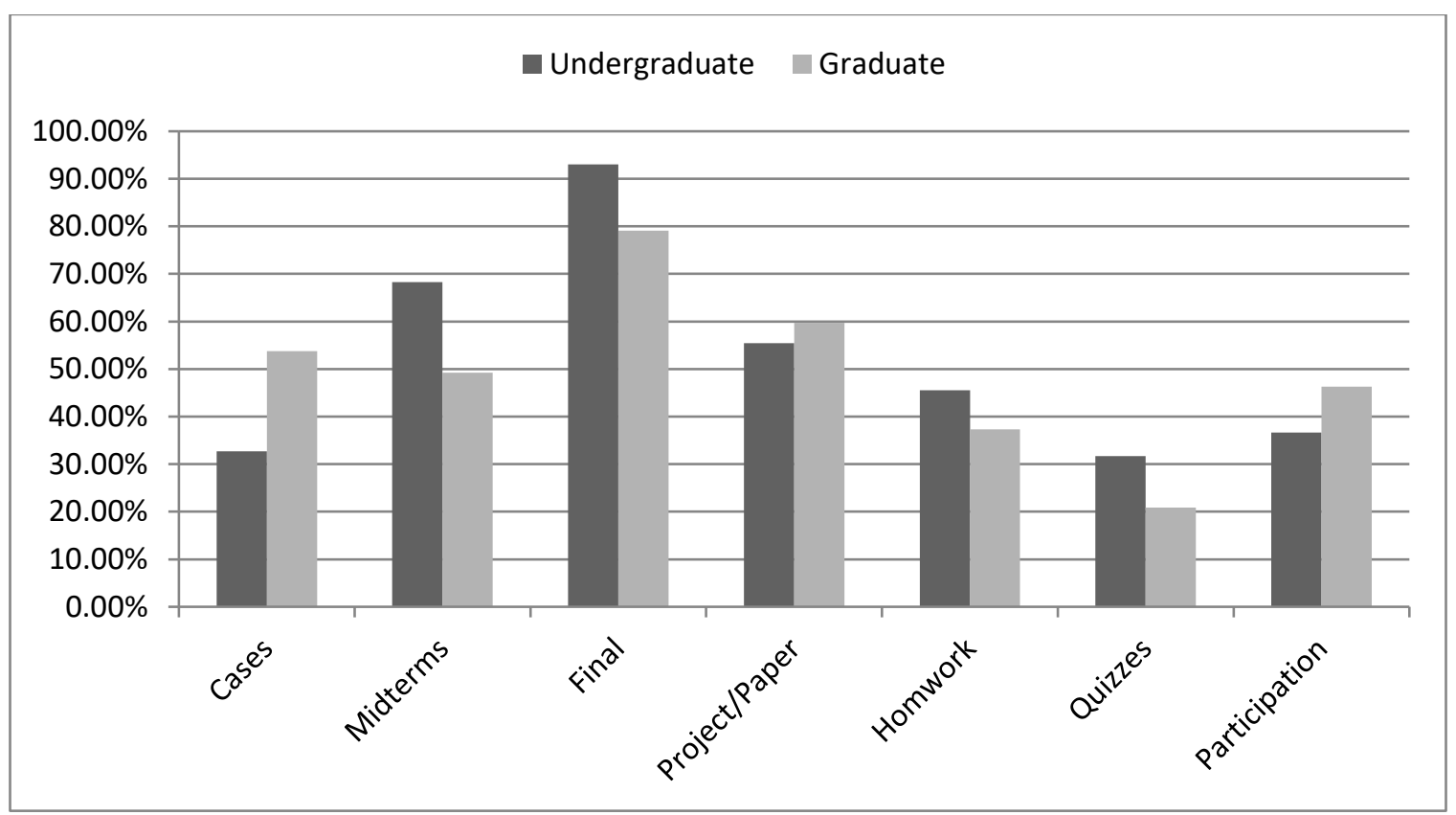

Course Topics 
Ninety-five undergraduate course syllabi gave details of topical content. This yielded total of 110 topics. Similarly, sixty-nine syllabi from graduate courses yielded 101 topics. To gauge the relative importance of each topic, the percentage of class time based on contact minutes was used as the measure of the topic's importance. In the event of missing data (i.e., syllabi which did not include number of meetings/week or class length), sample averages were used (Tsikriktsis 2005, Hair et al., 1998). Syllabi that did not include a course schedule with identified topics were excluded from the topic analysis.

Table 1 presents details of the most commonly observed topics included in undergraduate courses. While most of the topics on the list were as expected, there are some interesting observations. First, topics such as process design, supply chain management, and sales and operations planning were not among the most commonly included topics. While this might be in part due to differences in how topics were listed in syllabi, it nevertheless suggests wide variation in what is being taught. Second, there is significant variation in the relative importance attached to individual topics. Again, while this can be explained in part by individual instructor preferences and differences between core and specialty classes, it does suggest a lack of standards in content.

Table 1 Topics covered in undergraduate courses 


\begin{tabular}{|l|c|c|c|c|}
\hline \multirow{2}{*}{ Topic } & \multirow{2}{*}{ \# courses } & \multicolumn{3}{c|}{$\%$ of class time } \\
\cline { 3 - 5 } & & Average & Min & Max \\
\hline Introduction & 88 & $4.69 \%$ & $1.38 \%$ & $14.62 \%$ \\
\hline Inventory Management & 61 & $7.74 \%$ & $1.71 \%$ & $31.06 \%$ \\
\hline Quality Management & 61 & $4.21 \%$ & $0.00 \%$ & $24.85 \%$ \\
\hline Forecasting & 50 & $2.08 \%$ & $0.00 \%$ & $13.44 \%$ \\
\hline Strategy & 49 & $5.04 \%$ & $1.38 \%$ & $12.50 \%$ \\
\hline Project Management & 47 & $8.94 \%$ & $0.00 \%$ & $68.33 \%$ \\
\hline Capacity Analysis & 46 & $4.47 \%$ & $1.37 \%$ & $14.20 \%$ \\
\hline Lean & 46 & $4.65 \%$ & $0.00 \%$ & $64.71 \%$ \\
\hline Scheduling & 33 & $4.39 \%$ & $1.83 \%$ & $8.96 \%$ \\
\hline Location Analysis & 32 & $3.93 \%$ & $0.97 \%$ & $11.11 \%$ \\
\hline \multicolumn{4}{|c|}{ * Out of 95 courses analyzed } \\
\hline
\end{tabular}

The most commonly observed topics included in graduate courses are largely similar to those in undergraduate courses (Table 2). However, the percent of time devoted to topics was consistently higher. This suggests that at the graduate level, 'core' topics account for a relatively larger proportion of total course coverage.

Table 2 Topics covered in graduate courses

\begin{tabular}{|l|c|c|c|c|}
\hline \multirow{2}{*}{ Topic } & \multirow{2}{*}{ \# courses } & \multicolumn{3}{c|}{ \% of class time } \\
\cline { 3 - 5 } & & Average & Min & Max \\
\hline Introduction & 62 & $8.85 \%$ & $0.56 \%$ & $100.00 \%$ \\
\hline Inventory Management & 40 & $9.42 \%$ & $2.78 \%$ & $26.67 \%$ \\
\hline Strategy & 36 & $8.85 \%$ & $3.13 \%$ & $25.00 \%$ \\
\hline Quality Management & 33 & $13.19 \%$ & $0.56 \%$ & $100.00 \%$ \\
\hline Process Analysis & 31 & $13.97 \%$ & $0.56 \%$ & $100.00 \%$ \\
\hline Capacity Analysis & 29 & $6.73 \%$ & $1.56 \%$ & $26.67 \%$ \\
\hline Lean & 23 & $4.70 \%$ & $1.10 \%$ & $15.38 \%$ \\
\hline Forecasting & 21 & $6.56 \%$ & $1.10 \%$ & $20.00 \%$ \\
\hline Project Management & 21 & $13.42 \%$ & $3.13 \%$ & $66.67 \%$ \\
\hline Material Requirements Planning & 19 & $5.23 \%$ & $0.56 \%$ & $12.50 \%$ \\
\hline \multicolumn{4}{|c|}{ *Out of 69 courses analyzed } \\
\hline
\end{tabular}

Gap Analysis

One of the conclusions that can be drawn from the study by Visich and Khumawala (2006) is that no recent study has reconciled the academic preparation of students in OM 
with the needs of industry. While Basnet (2000) and Ebert et al. (1998) conducted studies in the context of New Zealand and Romania respectively, not since Taj et al. (1996) has a similar analysis been conducted in a U.S. context. Visich and Khumawala (2006) did however suggest that OM courses should address a mix of concepts and techniques in manufacturing, services, information technology, and issues of an international nature. They also suggested that while knowledge of techniques is important, the emphasis of courses needs to shift from techniques to concepts. An additional suggestion was that courses directed at students in executive/professional MBA programs should emphasize the strategic integration of $\mathrm{OM}$ with other business disciplines.

Absent a more definitive statement of the needs of industry as they relate specifically to OM, we rely on studies by Sodhi et al. (2008) and Johnson and Pyke (2000) of employer expectations relative to supply chain management more broadly to conduct a gap analysis. It should be noted that the focus of these works was on graduate level academic preparation. Nevertheless, they provide some context for exploring gaps between academia and industry as they relate to student preparation. Results are presented in Table 3.

With the exception of two topics, Marketing and Channel Restructuring, and Reverse Logistics and Green Issues, topics identified in our sample overlap with those identified by Sodhi et al. (2008) and Johnson and Pyke (2000). As most OM courses focus on manufacturing and service processes, it is not surprising that marketing and channel issues did not appear in OM course syllabi. It is however more surprising that green 
issues are not covered in OM classes. With organizations becoming increasingly sensitive to environmental issues, it is apparent that OM courses need to familiarize students with the corresponding concepts.

With regard to skills, Sodhi et al. (2008) identified that leadership skills were the most commonly identified in job postings. The syllabi in our sample however did not suggest that leadership skills are being developed in OM courses. While it is possible that students acquire leadership skills in other courses such as those on project management or team management, the results do highlight an opportunity for OM courses to develop leadership skills specific to the OM domain. The other skills identified by Sodhi et al. that were not highlighted in our sample, are in general more basic skills that that one would expect students to have acquired elsewhere in their educational process (e.g., communication, basic IT). They are however skills that OM courses have the opportunity to further develop. It is not surprising that programming skills are not covered in OM courses. The contemporary focus of business school curricula as it relates to software is on the use of application software tools rather than programming.

Table 3 Topics and Broad Skills covered in courses 


\begin{tabular}{|c|c|c|c|c|c|}
\hline & & $\begin{array}{c}\text { Current } \\
\text { Research } \\
\end{array}$ & $\begin{array}{c}\text { Current } \\
\text { Research }\end{array}$ & \begin{tabular}{|c|} 
Johnson \& \\
Pyke (2000) \\
\end{tabular} & \begin{tabular}{|c} 
Sodhi, Son \& \\
Tang (2008) \\
\end{tabular} \\
\hline & Course Level & Undergraduate & Graduate & Graduate & Graduate \\
\hline \multirow{12}{*}{ 응 } & Location and supply chain design & $\mathrm{x}$ & $\mathrm{x}$ & $\mathrm{x}$ & $\mathrm{x}$ \\
\hline & Transportation and logistics & $x$ & $\mathrm{x}$ & $x$ & $\mathrm{x}$ \\
\hline & \begin{tabular}{|l|} 
Inventory and forecasting \\
\end{tabular} & $\mathrm{x}$ & $\mathrm{x}$ & $\mathrm{x}$ & $\mathrm{x}$ \\
\hline & Marketing and channel restructuring & & & $x$ & $x$ \\
\hline & Sourcing and supplier management & $\mathrm{x}$ & $\mathrm{x}$ & $x$ & $\mathrm{x}$ \\
\hline & Information and electronic mediated environments & $x$ & $x$ & $x$ & $x$ \\
\hline & Product design and new product introduction & $\mathrm{x}$ & $\mathrm{x}$ & $x$ & $\mathrm{x}$ \\
\hline & Service and after sales support & $\mathrm{x}$ & $\mathrm{x}$ & $\mathrm{x}$ & $\mathrm{x}$ \\
\hline & Reverse logistics and green issues & & & $x$ & $\mathrm{x}$ \\
\hline & Outsourcing and strategic alliances & $\mathrm{x}$ & $x$ & $x$ & $x$ \\
\hline & Metrics and incentives & $\mathrm{x}$ & $\mathrm{x}$ & $x$ & $\mathrm{x}$ \\
\hline & Global issues & $x$ & $x$ & $x$ & $x$ \\
\hline \multirow{10}{*}{$\frac{\infty}{\overline{\bar{r}}}$} & Other operations management & $x$ & $x$ & & $x$ \\
\hline & General analytical & & $x$ & & $x$ \\
\hline & Basic IT & & & & $x$ \\
\hline & Communication & & & & $\mathrm{x}$ \\
\hline & Programming & & & & $x$ \\
\hline & Project & $\mathrm{x}$ & $x$ & & $x$ \\
\hline & Team & $x$ & & & $x$ \\
\hline & Statistics & $x$ & $\mathrm{x}$ & & $x$ \\
\hline & Leadership & & & & $x$ \\
\hline & Modeling & $x$ & $x$ & & $x$ \\
\hline \multirow{12}{*}{ 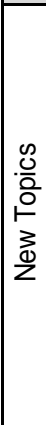 } & Spreadsheet and database & $x$ & $\mathrm{x}$ & & \\
\hline & Course administration & $x$ & $x$ & & \\
\hline & Strategy & $x$ & $x$ & & \\
\hline & JIT & $x$ & $\mathrm{x}$ & & \\
\hline & Process design and analysis & $\mathrm{x}$ & $\mathrm{x}$ & & \\
\hline & Quality & $x$ & $\mathrm{x}$ & & \\
\hline & Benchmarking & $x$ & $x$ & & \\
\hline & Scheduling & $x$ & $x$ & & \\
\hline & Planning & $x$ & $x$ & & \\
\hline & Lean Manufacturing & $x$ & $x$ & & \\
\hline & Risk Management & $x$ & $x$ & & \\
\hline & Reliability analysis & $x$ & $x$ & & \\
\hline
\end{tabular}

\section{Conclusions}

The goal of this research was to benchmark current educational practice in the area of

$\mathrm{OM}$ and to offer a picture of where OM education is and where it may need to go. A

significant amount of time has passed since prior efforts to empirically review the content

of OM courses, yet the field has undergone a number of changes. Our analysis suggests

that while OM education also continues to change, the change tends to be evolutionary

rather than revolutionary. The focus of undergraduate courses remains on providing

students with a general understanding and appreciation of the nature of OM, whereas at

the graduate level, courses take on a more strategic focus. It is not clear however whether 
earlier calls for a shift in focus from techniques to concepts has been heeded. Courses tend to emphasize the development of research based skills rather than market based skills. This presents an opportunity to instructors seeking to better align pedagogy with the needs of employers.

Larson \& Halldorsson (2004) and Wu (2007) raised the fact that faculty preferences/biases are an important factor in curricula design. This is perhaps a selfevident truth, but one that our results tend to support. Moreover, as Visich and Khumwala (2006) note, curricula are also constrained by a variety of institution specific constraints. Individual and institutional constraints notwithstanding, the challenge educators face is to ensure that they deliver products that are not only academically rich and rigorous, but adequately prepare students and meet the needs of other stakeholders. The analysis presented here suggests that while this is occurring, opportunities for improvement exist.

Opportunities also exist for further study in the domain of OM education. Our analysis is based on data obtained from members of the Institute for Supply Management and the Council for Supply Chain Management Professionals. The possibility that this sample frame may have biased the results cannot be overlooked. While academic members of these two organizations teach OM courses, their supply chain management orientation may have led to different priorities with regard to topical content and teaching style. The research also focused on self-selected courses. There may be other OM courses at institutions that participated in this study, as well as courses that cover operations topics but are not described as being OM courses. Moreover, it is possible that students acquire 
content and skills sought by employers in other coursework. Opportunities also exist to extend the present work. In particular, the number of syllabi from non U.S. institutions in the current database is small, precluding cross-national comparisons to be made. Examining the effectiveness of different curricula and pedagogical approaches also has the potential to offer fresh insights into OM education. 


\section{References}

Alstete, J. W. (1995) 'Benchmarking in Higher Education' in AHSE-ERIC Higher Education Report No. 5, Washington, DC., The George Washington University Graduate School of Education and Human Development.

Ahmad, N. 2013. Estimating trade in value-added: why and how? Global Value Chains in a Changing World.Ed by D.K. Elms and P. Low. 85-108. Published by World Trade Organization with the Temasek Foundation and the Fung Global Institute. Geneva, Switzerland.

The Association to Advance Collegiate Schools of Business. (2009) http://www.aacsb.edu/ (Accessed October 5, 2013)

Basnet, C. (2000) 'Production and Management in New Zealand: Is Education Relevant to Practice', International Journal of Operations and Production Management, Vol. 20 No. 6, pp. 730-744.

Caraway, R.L. and Freeland, J.R. (1989) 'MBA Training in Operations and Quantitative Methods', Interfaces, Vol. 19 No. 4, pp. 75-88.

Ducharme, R.E., and Lewis, D.A. (1987) 'The Academic/Practitioner Gap in Production and Inventory Management', Production and Inventory Management, Vol. 28 No. 1, pp. 88-95.

Ebert, R.J., Tanner, G., and Tuturea, M. (1998) 'Building the POM Curriculum for a Privatizing Economy: An Evaluation from Manufacturers' Perspectives', Production and Operations Management Journal, Vol. 7 No. 2, pp. 171-180.

Goffin, K. (1998) 'Operations Management Teaching on European MBA programmes', International Journal of Operations and Production Management, Vol. 18 No. 5, pp. 424-451.

Hair, Jr., J., Anderson, R. E., Tatham, R. L. and Black, W.C. (1998) Multivariate Data Analysis. Pearson Education, New York.

Hayes, R.H., Wheelwright, S.C. and Clark, K.B., Dynamic Manufacturing-Creating the Learning Organization, The Free Press, New York, NY, 189.

Jackson, N. (2001) 'Benchmarking in UK HE: an overview', Quality Assurance in Education, Vol. 9 No. 4, pp. 218-235.

Jeliazkova, M., and Westerheijden, D.F. (2002) 'Systemic adaptation to a changing environment: Towards a next generation of quality assurance models', Higher Education, Vol. 44 No. 3/4, Oct.-Dec., pp. 433-448.

Johnson, M.E., Pyke, D.F. (2000) 'A Framework for Teaching Supply Chain Management', Production \& Operations Management, Vol 9 No 10, pp 2-18.

Kolbe, R.H. and Burnett, M.S. (1991) 'Content-Analysis Research: An Examination of Applications with Directives for Improving Research Reliability and Objectivity', The Journal of Consumer Research, Vol 18 No 2, pp. 243-250. 
Larson P. \& Halldorsson A. (2004) 'Logistics versus supply chain management: an international survey', International Journal of Logistics, Vol 7 No 1, pp. 17-31.

Leslie, DW, and Fretwell Jr., E.K. (1996) Wise Moves in Hard Times: Creating \& Managing Resilient Colleges \& Unverisities. San Francisco: Jossey-Bass.

Lutz, H. and Birou, L. (2013) 'Logistics education: a look at the current state of the art and science', Supply Chain Management: An International Journal, Vol 18 No 4, pp. 455-467.

Raiszadeh, F.M.E. and Ettkin, L.P. (1989) 'POM in Academia: Some Causes for Concern', Production and Inventory Management Journal, Vol 30 No 2, pp. 37-40.

Sodhi, M.S., Son, B., and Tang, C.S. (2008) 'ASP, The Art and Science of Practice: What Employers Demand for Applicants for MBA-Level Supply Chain Jobs and the Coverage of Supply Chain Topics in MBA Courses', Interfaces, pp. 469-484.

Taj, S., Hormozi, A.M., and Mirshab, B. (1996) 'Undergraduate Academic Teaching and Manufacturing Industry Requirements: A Comparative Analysis', Interfaces, Vol 26 No 3, pp. 51-57.

Takeuchi, H. and Nonaka, I. (1994) 'The new product development game', Harvard Business Review, Vol.64 No.1, pp.77-86.

Trochim, B. and Donnelly, J. (2007) Research Methods Knowledge Base - Third Edition. Mason: Thompson.

Tsikriktsis, N. (2005) 'A review of techniques for treating missing data in OM survey research', Journal of Operations Management, Vol 24, pp 53-62.

van Hoek, R.I. (2001), 'Logistics education-achieving market and research driven skill development', International Journal of Physical Distribution \& Logistics Management, Vol 31 Nos 7/8, pp. 505-19.

VanWassenhove, L.N. and Corbey, M. (1998) 'Production and Operations Management Core Course Teaching at the Top 20 MBA Programmes in the USA'. Working Paper, INSEAD.

Visich, J.K., and Khumawala, B.M. (2006), 'Operations Management Curricula: Literature Review and Analysis', Journal of Statistics and Management Studies, Vol. 9 No 3, pp. 61-687.

Willis, T.H., and Bass, K. (1991) 'A Profile of Academic Offerings in Production/Operations Management', Operations Management Review, Vol 8 No 2, pp. 36-42.

Wu, Y-C. J. (2007) 'Contemporary logistics education: an international perspective'. International Journal of Physical Distribution \& Logistics Management, Vol 37 No 7, pp. 504-528 